\title{
Period 2 regulates neural stem/progenitor cell proliferation in the adult hippocampus
}

\author{
Laurence Borgs ${ }^{1}$, Pierre Beukelaers ${ }^{1}$, Renaud Vandenbosch ${ }^{1}$, \\ Laurent Nguyen ${ }^{1}$, Gustave Moonen ${ }^{1,2}$, Pierre Maquet ${ }^{2,3}$, Urs Albrecht ${ }^{4}$, \\ Shibeshih Belachew ${ }^{1,2}$ and Brigitte Malgrange*1
}

Address: ${ }^{1}$ Developmental Neurobiology Unit, Center for Cellular and Molecular Neurobiology, University of Liège, C.H.U. B36, 4000 Liège, Belgium, ${ }^{2}$ Department of Neurology, C.H.U. Sart Tilman, B35, 4000 Liège, Belgium, ${ }^{3}$ Cyclotron Research Center, University of Liège, B30, 4000 Liège, Belgium and ${ }^{4}$ Department of Medicine, Division of Biochemistry, University of Fribourg, Friboug, Switzerland

Email: Laurence Borgs - Laurence.borgs@student.ulg.ac.be; Pierre Beukelaers - pbeukelaers@student.ulg.ac.be; Renaud Vandenbosch - Renaud.Vandenbosch@student.ulg.ac.be; Laurent Nguyen - Inguyen@ulg.ac.be;

Gustave Moonen - G.Moonen@ulg.ac.be; Pierre Maquet - pmaquet@ulg.ac.be; Urs Albrecht - urs.albrecht@unifr.ch; Shibeshih Belachew - sbelachew@ulg.ac.be; Brigitte Malgrange* - bmalgrange@ulg.ac.be

* Corresponding author

Published: 27 March 2009

BMC Neuroscience 2009, 10:30 doi:10.1/86/147/-2202-10-30
Received: 6 January 2009

Accepted: 27 March 2009

This article is available from: http://www.biomedcentral.com/147I-2202/10/30

(C) 2009 Borgs et al; licensee BioMed Central Ltd.

This is an Open Access article distributed under the terms of the Creative Commons Attribution License (http://creativecommons.org/licenses/by/2.0), which permits unrestricted use, distribution, and reproduction in any medium, provided the original work is properly cited.

\begin{abstract}
Background: Newborn granule neurons are generated from proliferating neural stem/progenitor cells and integrated into mature synaptic networks in the adult dentate gyrus of the hippocampus. Since light/dark variations of the mitotic index and DNA synthesis occur in many tissues, we wanted to unravel the role of the clock-controlled Period2 gene ( $m$ Per2) in timing cell cycle kinetics and neurogenesis in the adult DG.

Results: In contrast to the suprachiasmatic nucleus, we observed a non-rhythmic constitutive expression of mPER2 in the dentate gyrus. We provide evidence that mPER2 is expressed in proliferating neural stem/progenitor cells (NPCs) and persists in early post-mitotic and mature newborn neurons from the adult DG. In vitro and in vivo analysis of a mouse line mutant in the mPer2 gene $\left(\right.$ Per2 $\left.{ }^{B r d m} /\right)$, revealed a higher density of dividing NPCs together with an increased number of immature newborn neurons populating the DG. However, we showed that the lack of $m$ Per2 does not change the total amount of mature adult-generated hippocampal neurons, because of a compensatory increase in neuronal cell death.

Conclusion: Taken together, these data demonstrated a functional link between the constitutive expression of mPER2 and the intrinsic control of neural stem/progenitor cells proliferation, cell death and neurogenesis in the dentate gyrus of adult mice.
\end{abstract}

\section{Background}

Recent findings have shed light on the integration of adult-born hippocampal dentate gyrus (DG) neurons into mature synaptic networks $[1,2]$. How and why these new neurons are formed has become an intriguing question [3]. Because the circadian clock machinery can control intrinsic regulation of cell proliferation in peripheral tissues [4] we hypothesized that clock genes might influence 
neural stem/progenitor cell (NPC) division in the central nervous system.

Adult hippocampal neurogenesis in mammals is a plastic process placed under the control of environmental stimuli, which is comparable to the regulation of circadian rhythms [5]. Hormonal cycles and psychosocial stress [6,7], serotonin metabolism [8], depression [9], aging $[10,11]$, physical activity [12], sleep deprivation [13] and enriched living conditions [14] influence the rate of neuronal renewal and survival in various adult organisms. This suggests that mechanisms controlling life-long neurogenesis in the postnatal CNS are adapted to complex extrinsic inputs. Neurogenesis appears to be regulated by such physiological and behavioural parameters that are somehow connected to the circadian clock that synchronizes itself to changing environmental conditions to optimize an organism's performance. Recent work has consistently shown a diurnal rhythm of neurogenesis among the olfactory projection neurons in the crustacean brain, with peak of neuroblasts proliferation during the hours surrounding dusk, the most active period for lobsters [15]. These data suggest the possibility that light-controlled rhythms may be primary regulators of neuronal proliferation, and that previously demonstrated hormonal and activity-driven influences over adult neurogenesis may be secondary events in a complex circadian control pathway.

Intriguingly, the expression of circadian genes that belong to the intracellular clock of the suprachiasmatic nucleus (SCN) have also been described in other brain areas, in peripheral organs and even in immortalized cell lines in culture $[16,17]$. The mPer 2 gene is one of the three mammalian orthologs (mPer1, mPer2 and mPer3) of the Drosophila circadian clock gene period $[18,19]$. In situ hybridization experiments have established that mPer1 and $m P e r 2$ genes are expressed in the hippocampus and particularly in the DG where their function remains elusive [18]. The rate of cell cycle kinetics and neurogenesis are tightly coupled in the adult mammalian DG. The overall duration of the cell cycle in hippocampal neuronal precursor cells is about 24 hours [20] and very close if not identical to the circadian period. There is already substantial in vivo evidence that outside the mammalian brain, circadian rhythms control the timing of cell division [4]. Accordingly, light/dark variations of the mitotic index and DNA synthesis occur in many tissues, i.e. oral mucosa [21], tongue keratinocytes [22], liver [4], skin [23] and bone marrow [24].

In the present work, we wanted to decipher whether mPER2, one of the central component of the circadian clock machinery, regulates the proliferation and the maturation of NPCs into granule neurons in the hippocampal
DG of adult mice. We used the Per $2^{\text {Brdm } 1}$ mutant mice line to assess the specific requirement of $m P e r 2$ in adult neurogenesis. Here, we showed that mPER2 was non-rhythmically expressed in the granule neuronal lineage in the adult DG. In adult Per $2^{\mathrm{Brdm} 1}$ mice, we found an increase in both the proliferation of NPCs and the number of immature granule neurons expressing DCX and NeuroD. Strikingly, the pool of adult generated mature granule cells was not enlarged, as one would expect. The accumulation of supernumerary mature granule cells was prevented by apoptosis in the DG of Per $2^{B r d m 1}$ mice. Our results suggest that mPer2 belongs to the molecular machinery that underlies the course of adult hippocampal neurogenesis by regulating the early cellular events leading to the production of post-mitotic granule cells in the DG.

\section{Results \\ Constitutive expression of mPER2 in the adult dentate gyrus}

The expression profile of MPER2 in the DG region of the hippocampus was established by immunohistochemistry using two different polyclonal antibodies on $40 \mu \mathrm{m}$-thick coronal sections from P45 adult male mice. Both antimPER2 antibodies lead to similar expression patterns (See Additional file 1A-B). mPER2 was highly expressed throughout the adult hippocampus and particularly in the granule cell layer (GCL), subgranular layer (SGL) and the hilus $(\mathrm{H})$ of the DG (Fig. 1A). In order to determine whether MPER2 expression levels could undergo rhythmic oscillations in the DG, immunostainings and Western blots were performed at several circadian time points including ZT0, ZT6, ZT12 and ZT18. Surprisingly, immunolabellings revealed that the level of mPER2 was comparable throughout circadian ZTs (fig. 1E). In contrast, mPER2 expression displayed circadian oscillations in the SCN with a peak of expression at ZT12 (compare fig. 1C and fig. 1D) as previously shown $[18,25,26]$. Western blots analysis performed on micro-dissected DG confirmed that mPER2 levels were constitutively stable with time, as previously described for its transcript [27], as compared to the SCN, where the maximum of mPER2 expression occurs at ZT12 (Fig. 1F).

\section{mPER2 is expressed by NPCs and throughout the granule cell lineage in the adult dentate gyrus}

In order to define the phenotypic identity of mPER2+ cells in the adult DG, we performed immunohistochemical stainings with cell type-specific markers. The adult DG contains several cell types including glia-like stem cells $\left(\mathrm{SOX}^{+} / \mathrm{S}\right.$ 00B $\left.-\mathrm{GFAP}^{+}\right)$, transiently amplifying proliferating precursor cells $\left(\mathrm{SOX}_{2}+\mathrm{Ki}^{+} 7^{+}\right.$, some are $\mathrm{NeuroD}^{+}$and $\left.\mathrm{DCX}^{+}\right)$, proliferating neuroblasts $\left(\mathrm{SOX}^{-} / \mathrm{DCX}^{+} / \mathrm{NeuroD}^{+} /\right.$ $\left.\mathrm{Ki}^{6} 7^{+}\right)$immature neurons $\left(\mathrm{DCX}^{+} / \mathrm{NeuroD}^{+} / \mathrm{Ki}^{-} 7^{-}\right)$, mature neurons $\left(\mathrm{NeuN}^{+}\right)$astrocytes $\left(\mathrm{SOX}^{+} / \mathrm{S} \mathrm{SOOB}^{+} /\right.$ $\mathrm{GFAP}^{+}$) and oligodendrocytes $\left(\mathrm{CNPase}^{+}\right)[28,29]$. We 

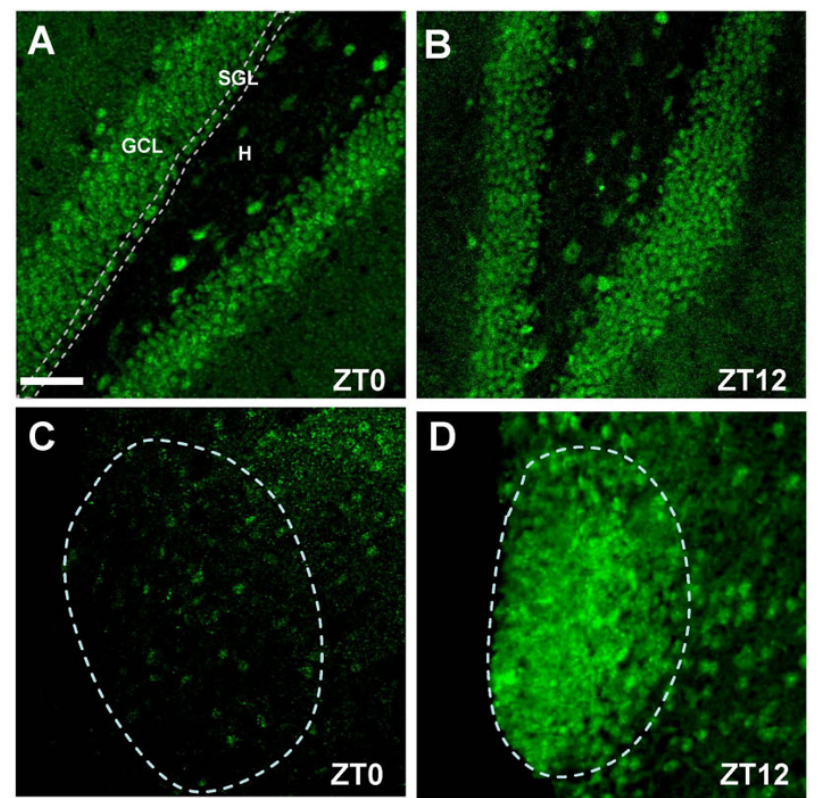

E
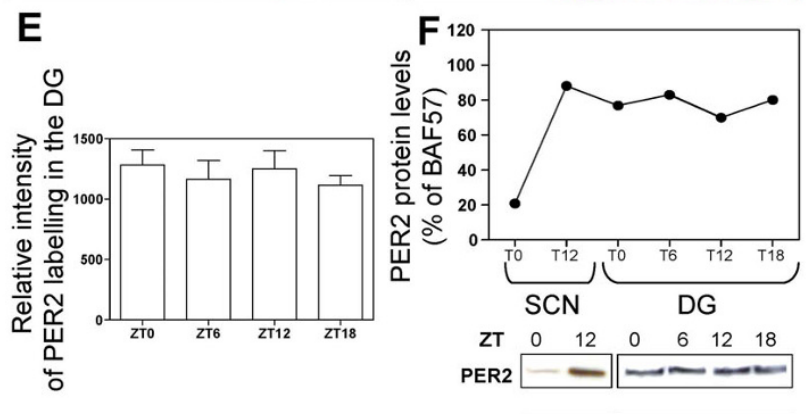

BAF57 $---\infty$

\section{Figure I}

The MPER2 protein is constitutively expressed in the adult dentate gyrus. (A-B) Confocal images illustrating the expression of $m P E R 2$ in the granule cell layer (GCL), hilar region $(\mathrm{H})$ and subgranular layer $(\mathrm{SGL})$ of the dentate gyrus (DG) from P45 WT mice. No circadian oscillation of mPER2 expression is observed in the DG. (C-D) On the contrary, mPER2 is highly rhythmic in the SCN with a minimum of mPER2 expression at ZT0 (C) and a maximum of mPER2 expression at ZTI2 (D). (A-D) Images represent «Z-stack» overlays from $40 \mu \mathrm{m}$-thick coronal sections of 5 adjacent confocal planes (step size $=I \mu \mathrm{m}$ ). (E) The intensity of mPER2 labelling is constant at different circadian time points, i.e. ZT0, ZT6, ZTI 2 and ZTI 8 (mean \pm SD, $n=3$ independent experiments). (F) Levels of PER2 expression were analyzed by Western blot. Analysis were carried out on nuclear protein extracts from micro-dissected SCN and DG (at ZT0, ZT6, ZTI2 and ZTI8) of P45 WT mice, incubated with mPER2 antibody and BAF57 antibody as internal control. mPER2 antibody yielded a band at the expected size (I36 $\mathrm{KDa}$ ). Results were expressed as percentage of BAF57. Scale bar in $A=50 \mu \mathrm{m}$ for $A-B$ and $25 \mu \mathrm{m}$ for $C-D$. never found any SOX2+/Ki67-/mPER2+ cells (data not shown), indicating that glial-like stem cells are mPER2 negative. We observed that some transit amplifying progenitors SOX2+/KI67+ expressed mPER2 (Fig. 2A-D). In
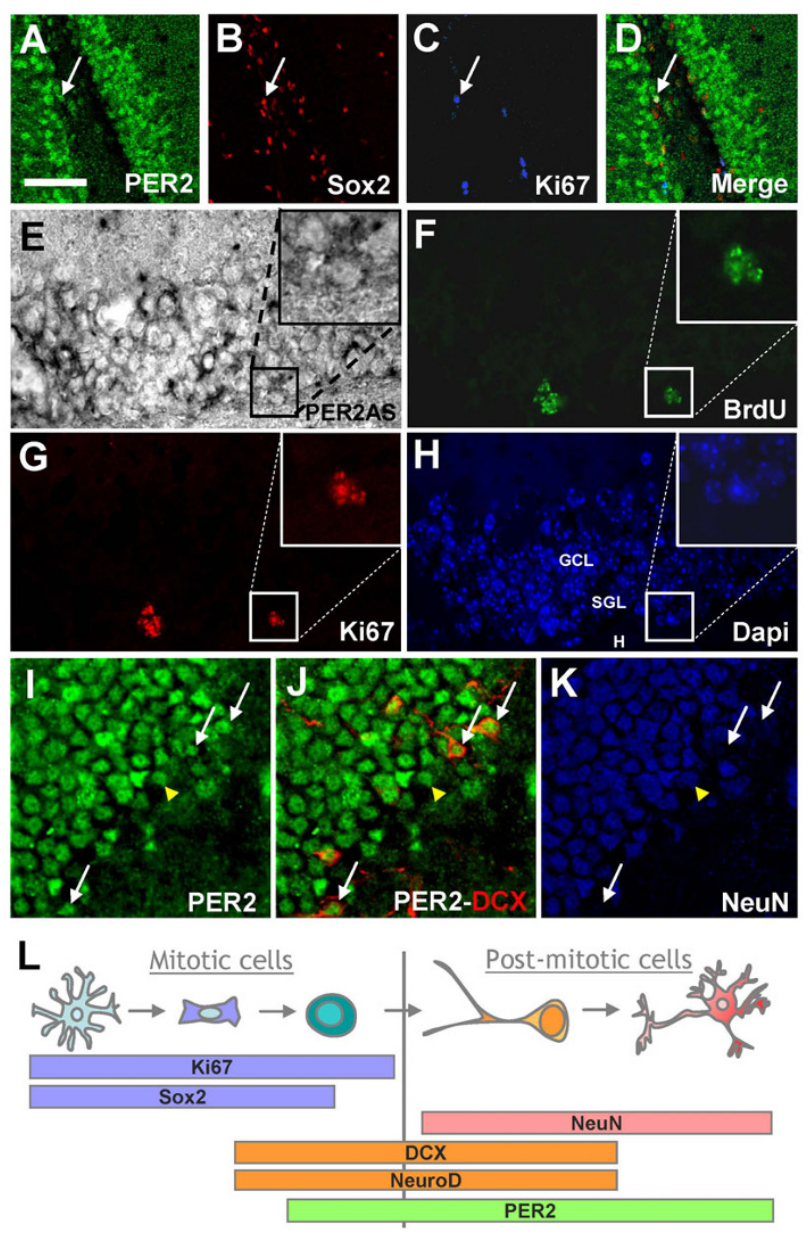

Figure 2

Phenotype of mPER2-expressing cells in the adult dentate gyrus. (A-D) Confocal images showing some undifferentiated dividing Sox $2^{+}(\mathrm{B})$ and $\mathrm{Ki}^{+} 7^{+}(\mathrm{C})$ cells located in the SGL expressing mPER2 (D). (E-H) mPer2 mRNA distribution in the $G C L$ revealed by in situ hybridization $(E)$ and immunostained for BrdU (F) (one i.p. injection at $100 \mathrm{mg} / \mathrm{kg}$ of body weight) and $\mathrm{Ki67}(\mathrm{G})$. (H) DAPI was used for nuclear counterstaining. Insets show a mPER2 ${ }^{+}$cell also labelled for $\mathrm{BrdU}(\mathrm{F})$ and $\mathrm{Ki} 67(\mathrm{G})$. (I-J) Immature neural precursor $\mathrm{DCX}^{+}$were found to be mPER2 ${ }^{+}(\mathrm{J}$, white arrows). (I and $\mathrm{K}$ ) All the mature neurons expressing $\mathrm{NeuN}$ were found to be mPER2 ${ }^{+}$(yellow arrowhead), white arrows point towards $\mathrm{mPER} 2^{+} / \mathrm{NeuN}$ - cells. (A-K) All images represent «Z-stack» overlays from $40 \mu \mathrm{m}$-thick coronal sections of 5 adjacent confocal planes (step size $=I \mu \mathrm{m}$ ). (L) Schematic representation of the mPER2 expression in mitotic and post-mitotic cells of the DG. Scale bar in A = $30 \mu \mathrm{m}$ for A-D and I-K, 50 $\mu \mathrm{m}$ for $\mathrm{E}-\mathrm{H}$. 
situ hybridization with antisense mPer2 probe, followed by immunohistochemistry, confirmed the expression of mPer2 mRNA dividing $\mathrm{Ki}^{+} 7^{+}$and $\mathrm{BrdU}^{+}$cells of the SGL (Fig. 2E-H). Labelling was absent in control sections hybridized with sense probe (data not shown). We quantified dividing cells expressing mPER2 in the adult DG and found that $21,52 \% \pm 13,3 \%$ of Ki67+cells expressed mPER2 (mean $\pm S D, n=4$ ). NeuroD and DCX are indeed expressed early in the lineage-determined neuronal cells in the adult hippocampus, i.e. in precursor cells to immature neurons. We observed that some mPER2+ cells expressed DCX and are NeuN negative (Fig. 2I-K), suggesting that mPER2 is expressed in proliferating $\mathrm{DCX}^{+}$precursor cells. Using double immunostainings to detect mPER2 in immature and mature neurons, we found 79,8 $\pm 7,6 \%$ of NeuroD ${ }^{+-}, 70,5 \pm 4,3 \%$ of $\mathrm{DCX}^{+}$neuroblasts and $100 \%$ of $\mathrm{NeuN}^{+}$neurons (mean $\pm \mathrm{SD}, \mathrm{n}=3$ ) expressed mPER2. Altogether, our findings indicate that in the neuronal lineage, mPER2 expression starts in immature proliferating cells and persists in mature neurons (Fig. 2L).

While mPER2 was not expressed by astrocytes (See Additional file 2A-D) nor oligodendroglial lineage [30] (See Additional file $2 \mathrm{E}-\mathrm{G}$ ), some GABAergic interneurons of the SGL and the hilus were MPER2+ (See Additional file $2 \mathrm{H}-\mathrm{J})$.

\section{The pool of adult hippocampal NPCs is increased in Per2BrdmI mice}

To define whether mPer2 controlled the proliferation of hippocampal NPCs, we analyzed the DG of P45 WT and Per $2^{\text {Brdm } 1}$ male littermates [27] and observed a significant increase in the total number of $\mathrm{Ki} 67^{+}$cells in the DG of Per $2^{\text {Brdm } 1}$ mice as compared to WT (Fig. 3A-C) (mean \pm $\left.\mathrm{SD}, \mathrm{n}=7,{ }^{* * *} \mathrm{p}<0,001\right)$. Moreover, short-pulsed BrdU incorporation assays (i.e. 2 hours) revealed an increase in S-phase cells in the DG of Per2 ${ }^{\mathrm{Brdm} 1}$ mice (Fig. 3D-F) (mean $\left.\pm \mathrm{SD}, \mathrm{n}=7,{ }^{*} \mathrm{p}<0,05\right)$. Altogether, these results support a role for $m$ Per 2 in the regulation of the proliferation of NPCs in the adult DG.

\section{mPer 2 mutation results in an excess of newly formed neurons in the subgranular layer of the adult dentate gyrus} In comparison to WT animals, the number of immature neurons expressing NeuroD (Fig. 4A-C) and DCX (Fig. $4 \mathrm{D}-\mathrm{F}$ ) was significantly increased in the SGL of mPer2 mutant mice (mean $\left.\pm \mathrm{SD}, \mathrm{n}=4,{ }^{*} \mathrm{p}<0,05\right)$. We designed a "short-term" birthdating BrdU incorporation experimental protocol to assess neurogenesis during a short time window of 4 days. In agreement with the expansion of the pool of immature $\mathrm{DCX}^{+}$and NeuroD ${ }^{+}$cells, we observed a 3-fold increase of $\mathrm{BrdU}^{+} / \mathrm{NeuroD}^{+}$immature newborn neurons in the DG of Per $2^{\mathrm{Brdm} 1}$ mice as compared to WT (Fig. 4G-I)(mean $\left.\pm \mathrm{SD}, \mathrm{n}=4,{ }^{*} \mathrm{p}<0,05\right)$.
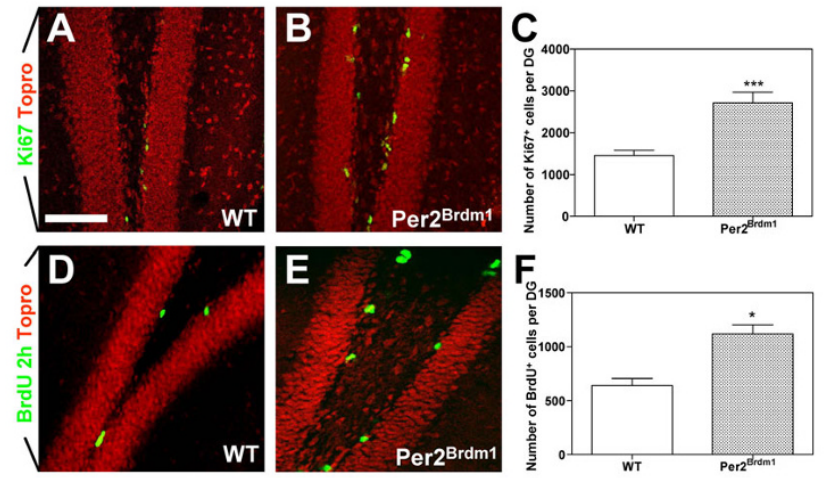

Figure 3

The mutation of the $\mathrm{mPer2}$ gene increases the number of proliferating NPCs in the adult dentategyrus. (A-B) Images displaying $\mathrm{Ki}^{+} 7^{+}$cells $(\mathrm{A}-\mathrm{B})$ and $\mathrm{BrdU}^{+}$ cells (D-E) (one i.p. injection at $100 \mathrm{mg} / \mathrm{kg}$ of body weight and sacrifice 2 hours later) in the DG from P45 WT (A and D) and $\operatorname{Per} 2^{\mathrm{Brdm} I}$ ( $\mathrm{B}$ and $\left.\mathrm{E}\right)$ mice. TO-PRO ${ }^{\circledR}-3$ was used for nuclear counterstaining. All images represent «Z-stack» overlays on $40 \mu \mathrm{m}$-thick coronal sections of 5 adjacent confocal planes (step size $=I \mu \mathrm{m})$. $(\mathrm{C}$ and $\mathrm{F}$ ) Histograms representing an unbiased assessment of the number of $\mathrm{Ki}^{+}(\mathrm{C})$ and $\mathrm{BrdU}^{+}(\mathrm{F})$ cells (mean $\pm \mathrm{SD}, \mathrm{n}=7$, Student's t-test, *** $\mathrm{p}<$ 0,00 I, $\left.{ }^{*} p<0,05\right)$. Scale bar in $A=50 \mu \mathrm{m}$ for $A-B ; D-E$.

\section{mPer2 regulates the proliferation and differentiation of NPCs in vitro}

To correlate the selective increase of adult NPCs proliferation and neuroblasts differentiation in the DG of Per $2^{\text {Brdm } 1}$ mutant mice with a functional in vitro assessment of their proliferative potential ant their multi-lineage differentiation capacity, we compared the potential of WT and Per $2^{\text {Brdm } 1}$ NPCs from the DG to form neurospheres and to differentiate into neurons. We showed that Per2 ${ }^{\text {Brdm } 1}$ NPCs generated significantly larger neurospheres compared with corresponding cells from WT mice (Fig. 5A-B). A careful analysis of the size of secondary neurospheres showed that Per $2^{\text {Brdm } 1}$ NPCs generated a reduce number of spheres within the range of 50-100 $\mu \mathrm{m}$ diameter and a significant increase in the number or spheres within $>150$ $\mu \mathrm{m}$ range (Fig. 5C) $\left(\mathrm{n}=3\right.$, mean $\pm \mathrm{SEM},{ }^{* * *} \mathrm{p}<0,001$ and $\left.{ }^{*} \mathrm{p}<0,05\right)$.

To investigate whether the lack of mPer 2 regulates the differentiation of neurosphere composing cells, we plated neurospheres 5 days in differentiating condition. These cells generate astrocytes, oligodendrocytes (data not shown) and neurons (Fig. 5E and fig. 5F) in both genotypes. Among the progeny of $\operatorname{Per} 2^{\mathrm{Brdm} 1}$ neurospheres, we observed a significant increase of differentiated neurons $\left(\right.$ Tuj $\left.1^{+}\right)$(Fig. 5D-F) (mean \pm SEM, $\left.n=3,{ }^{*} \mathrm{p}<0,05\right)$. Conversely, similar percentages of differentiated astrocytes $\left(\mathrm{GFAP}^{+}\right)$and oligodendrocytes $\left(\mathrm{O}^{+}\right)$were found in both 

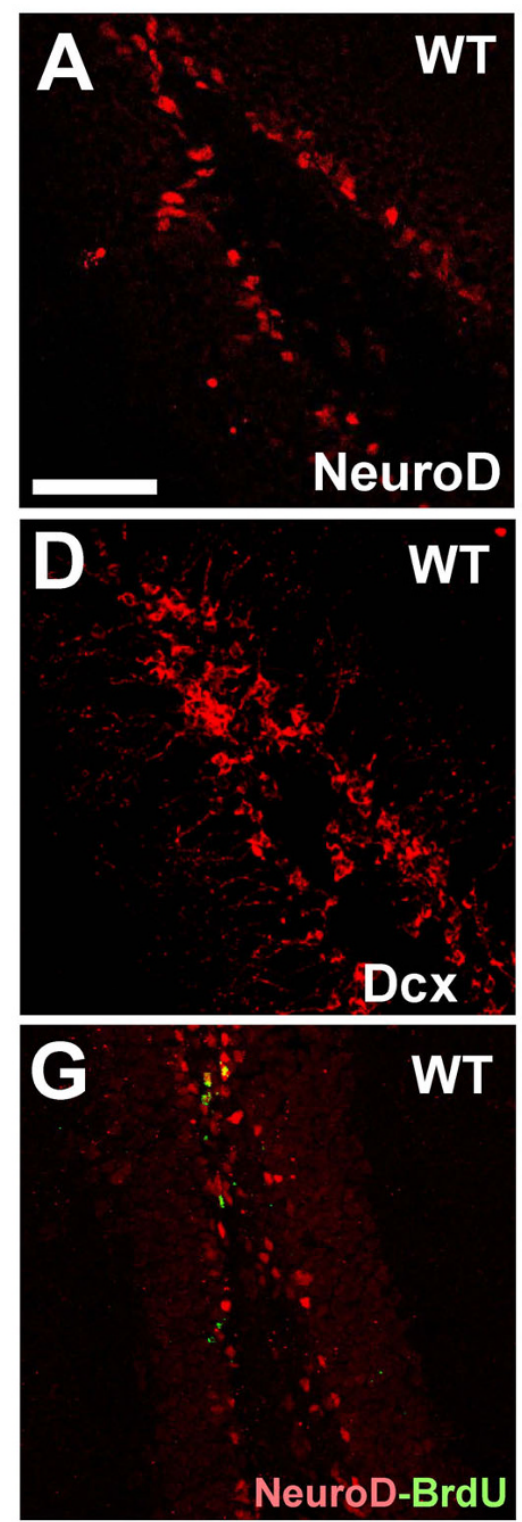
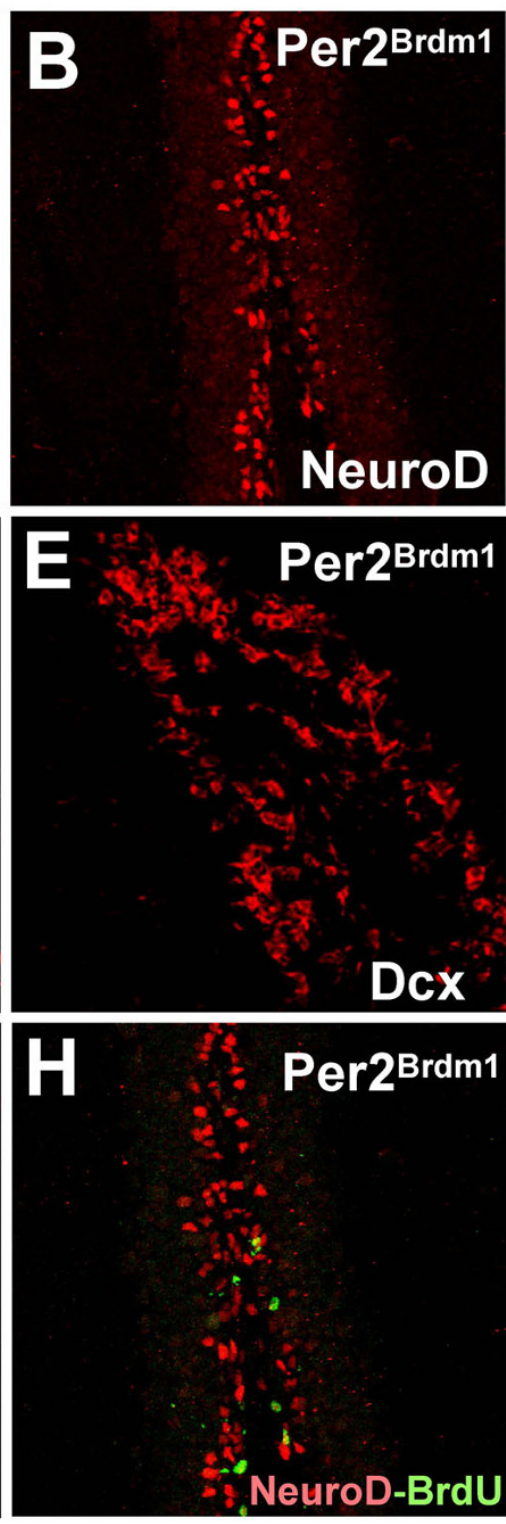
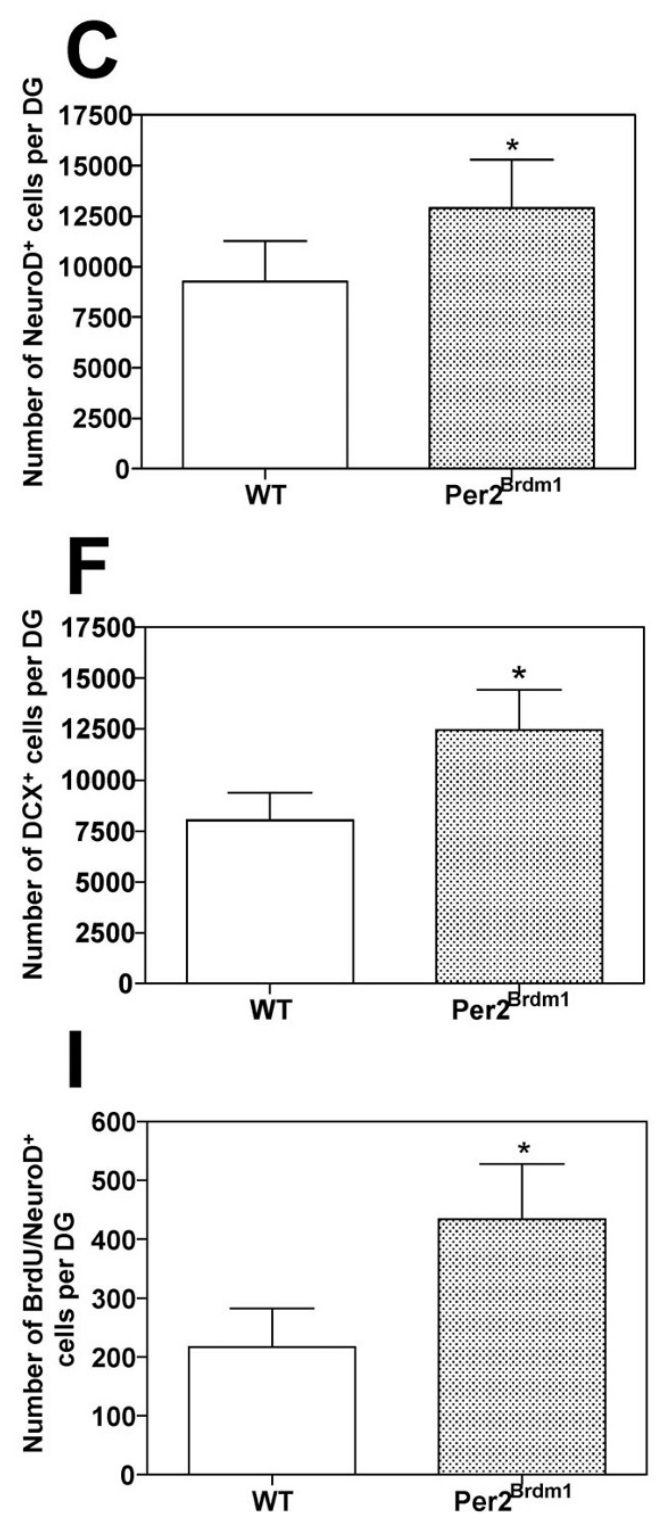

Figure 4

Increased number of early newborn NeuroD- and DCX-expressing neurons in Per2 ${ }^{\mathrm{Brdm} I}$ mutant mice. DG of P45 WT $(A ; D ; G)$ and Per2BrdmI $(B ; E ; H)$ mice were immunostained for NeuroD $(A-B ; G-H)$ and $D C X(D-E)$. Total NeuroD $(C)$ and $\mathrm{DCX}^{+}(\mathrm{F})$ cells per section were quantified (mean $\pm \mathrm{SD}, \mathrm{n}=4$, Student's $t$-test, $\left.{ }^{*} \mathrm{p}<0,05\right)$. (G-I) Assessment of the "shortterm" neurogenesis. WT and Per2 $2^{\mathrm{rdm} /}$ adult mice received a single injection of BrdU (i.p. injection at $100 \mathrm{mg} / \mathrm{kg}$ of body weight) and were sacrificed 4 days later. (G-H) DG sections were immunostained with anti-BrdU (green) and anti-NeuroD (red) antibodies. All images represent «Z-stack» overlays on $40 \mu \mathrm{m}$-thick coronal sections of 5 adjacent confocal planes (step size $=$ I $\mu \mathrm{m})$. (I) Histograms representing the assessment of the number of immature newborn $\mathrm{BrdU}^{+} / \mathrm{NeuroD}^{+}$neurons per $\mathrm{DG}$ (mean $\pm S D, n=4$, Student's $t$-test, $\left.{ }^{*}<<0,05\right)$. Scale bar in $A=50 \mu \mathrm{m}$ for $A-H$.

genotypes (data not shown). Altogether, these in vitrodata confirmed our in vivo results and strongly support mPer2 as a key player regulating both the proliferation and the neuronal differentiation of NPCs derived from the DG of adult mice.
Increased apoptotic cell death eliminates supernumerary newborn neurons in the dentate gyrus of adult Per ${ }^{2 \mathrm{BrdmI}}$ mice

We performed "long-term" birthdating BrdU incorporation assays to analyze the final fate and survival of newly 

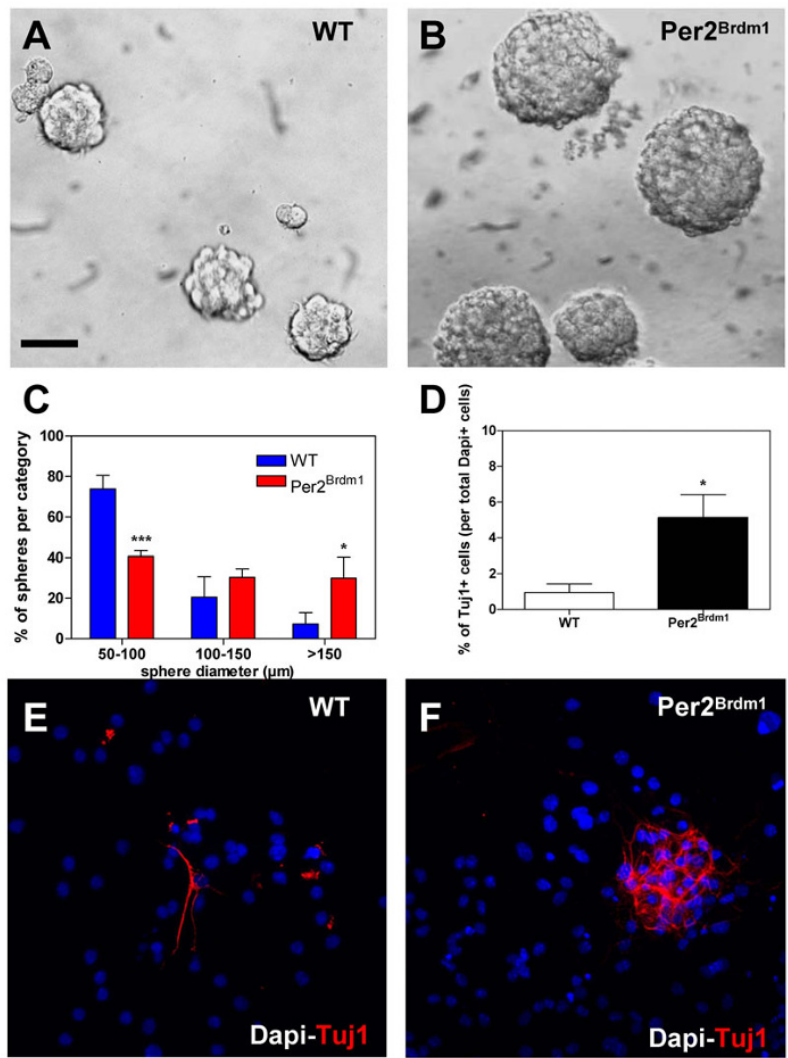

\section{Figure 5}

mPer2 mutation increased in vitro neural stem/progenitor cell proliferation and differentiation. (A-C)

Representative neurosphere morphologies and size categories for DG of adult P45 WT and Per2 ${ }^{\mathrm{Brm} /}$ mice. (C) Spheres were categorized into 3 size groups: (I) 50-100 $\mu \mathrm{m},(2) 100-$ $150 \mu \mathrm{m}$ and (3)> $150 \mu \mathrm{m}$ in diameter. Data were obtained from three independent experiments and are expressed as mean \pm SEM $\left(* * * p<0,001\right.$ and $*_{p}<0,05$ were analyzed by student's $t$-test). (D-F) Differentiating adult NSC cultures for 5 days in vitro on poly-L-ornithin and laminin immunostained for $\beta$-III tubulin (TujI, red) and DAPI (blue). Increased percentage of neurons was obtained for Per2Brdml differentiated neurospheres as compared to WT (D). Results are expressed as mean \pm SEM ( $n=3$ independent experiments, $*_{p}<0,05$ analyzed by student's $t$-test). Scale bar in $A=100$ $\mu \mathrm{m}$ for $A-B$ and $50 \mu \mathrm{m}$ for $E-F$.

formed neurons. Animals were sacrificed 21 days after the end of BrdU injection period. In contrast with the results obtained using a "short-term" BrdU incorporation protocol, we found no difference in the number of mature granule neurons $\mathrm{BrdU}^{+} / \mathrm{NeuN}^{+}$in the $\mathrm{DG}$ of both WT and Per $2^{\text {Brdm } 1}$ mice (Fig. 6A-D) (mean \pm SD, $\mathrm{n}=9$ for WT mice and $\mathrm{n}=6$ for Per $\left.2^{\text {Brdm1 }}, \mathrm{p}=0,9641\right)$.

It is established that during the first 2 to 3 weeks following cell cycle exit, only a fraction of adult-born neurons are functionally integrated into the neuronal network of the DG while most newly formed neurons are naturally dying through apoptosis [20,31]. We thus performed TUNEL stainings to analyze the apoptotic cell death occurring in the DG of Per $2^{\text {Brdm } 1}$ and WT male littermates (Fig. 6E-G). The number of TUNEL+ cells was significantly increased in the DG of the Per $2^{\text {Brdm } 1}$ mutant mice as compare to WT (Fig. 6E-G) (mean $\left.\pm \mathrm{SD}, \mathrm{n}=4,{ }^{*} \mathrm{p}<0,05\right)$. Some TUNEL ${ }^{+}$ cells were also co-labelled with BrdU (using the "shortterm" birthdating assay) indicating that dying cells were newborn neurons (Fig. 6H-J). These results suggest that the newborn NeuroD ${ }^{+} / \mathrm{DCX}^{+}$cells in $\operatorname{Per} 2^{\mathrm{Brdm} 1}$ mice are cleared from the DG through apoptosis (Fig. 6H-J).

\section{Discussion}

The importance of the SCN to generate a multitude of circadian rhythms [32] suggests that most peripheral tissues, including other areas of the brain, are also likely to be under the "circadian" control of the SCN. Our data show that mPER2 clock protein expression is not oscillating in the murine adult DG. This is the first demonstration suggesting that a mammalian clock protein is constitutively expressed in a specific region of the adult brain. Previous findings in agreement with this observation showed a non-circadian expression of mPer 2 mRNA in the adult DG [18], thymus [33] and testes [34].

It is commonly established that the adult DG is composed of several cell types that include quiescent or slowly dividing and highly proliferating NPCs, immature and mature neurons [29]. Our results indicated that mPER2 expression starts in proliferating NPCs and remains sustained in newborn neurons from the early post-mitotic stage up to mature granule neuronal stage. Similar to the adult DG, murine testes and thymus also retain, to a certain extent, self-renewal capacities during adulthood [34,35]. In these organs, the constant expression of circadian clock gene, including mPER2, strongly suggest that this constitutive expression is a general feature of adult differentiating tissues and that these genes may have new clock-unrelated functions [34].

We wanted here to characterize the putative functions of mPer2 in the DG of the hippocampus during adult neurogenesis. Our results indicate that a functional impairment of $m$ Per2 (i.e. Per $2^{\text {Brdm } 1}$ mice) increased both the number of proliferating NPCs and the production of immature newborn neurons in the DG of adult mice. Hence, the increased number of early newborn post-mitotic neurons that we observed in the DG of Per $2^{B r d m} 1$ mice provided evidence that the expansion in the NPCs pool is not attributable to a delayed cell cycle exit. In line with our in vivo findings, in vitro analyze revealed that cultured NPCs isolated from the DG of $m P e r 2^{B r d m} 1$ mice generated larger neurospheres as compared to WT. This result argues in favour of mPer 2 control of NPCs proliferation in neuro- 

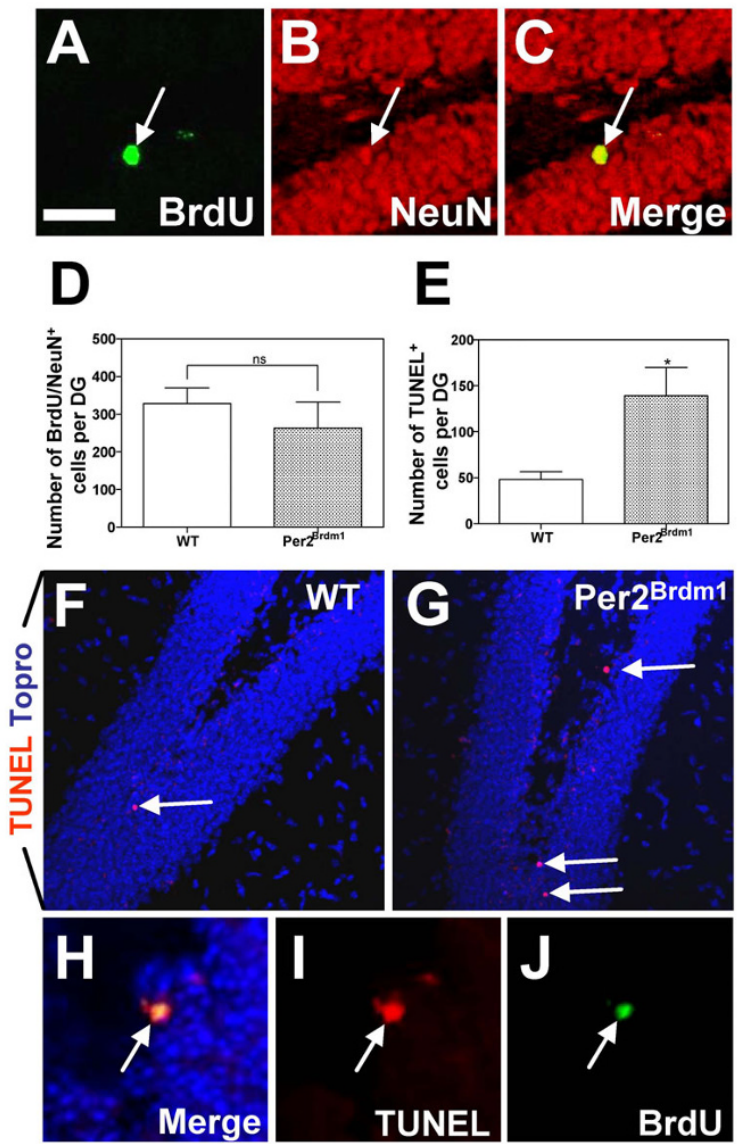

Figure 6

mPer2 mutation does not affect end-stage neurogenesis in the adult dentate gyrus because of a compensatory increase in apoptotic cell death. To assess the "long-term" neurogenesis, WT and Per2BrdmI mice received a daily injection of BrdU (i.p. injection at $100 \mathrm{mg} / \mathrm{kg}$ of body weight) during 5 consecutive days and were sacrificed 3 weeks after the last injection. (A-C) «Z-stack» overlays on $40 \mu \mathrm{m}$-thick coronal sections of 5 adjacent confocal planes (step size $=1 \mu \mathrm{m})$ displaying the DG of P45 WT mice exposed to the "long-term" BrdU incorporation protocol and stained for BrdU (A), for NeuN (B), or both (C) (white arrow points towards a $\mathrm{BrdU}^{+} / \mathrm{NeuN}^{+}$neuron). (D) Histograms representing the overall number of mature newborn $\mathrm{BrdU}^{+} / \mathrm{NeuN}^{+}$neurons in the DG of WT and $\mathrm{Per} 2^{\mathrm{Brdm} I}$ mice (mean \pm SD, $n=9$ for WT mice and $n=6$ for Per2Brdml, Student's t-test, $p>0,05$ ). (F-G) Confocal images displaying TUNEL+ cells in the DG of P45 WT (F) and Per2Brdm I mutant mice $(G)$. TO-PRO ${ }^{\circledR}-3$ was used for nuclear counterstaining. (E) Total number of TUNEL ${ }^{+}$cells (per $40 \mu$ m-thick DG section) displays a significant difference between WT and Per2 ${ }^{B r d m l}$ mice (mean $\pm S D, n=4$, Student's $t$-test, ${ }^{*} p<0,05$ ). $(\mathrm{H}-J)$ Newborn cell in the SGL of the DG expressing BrdU, (one i.p. injection of BrdU and sacrifice 4 days later i.e. "short-term" neurogenesis assay) is TUNEL ${ }^{+}$. Scale bar in $\mathrm{A}=$ $30 \mu \mathrm{m}$ for $\mathrm{A}-\mathrm{C}$ and $\mathrm{H}-\mathrm{J}, 50 \mu \mathrm{m}$ for $\mathrm{E}-\mathrm{F}, \mathrm{ns}=$ non significant. spheres. In addition, the number of neurons generated from $m P e r 2^{\mathrm{Brm} 1}$ neurospheres significantly increased, suggesting that $m P e r 2$ regulates the differentiation NPCs into postmitotic neurons. Altogether, these observations obtained from complementary models strongly support a dual function for mPER2 during adult neurogenesis. Our data support the circadian gene mPer2 as a new intrinsic regulator of both the proliferation and differentiation in NPCs of the adult murine DG. Interestingly, mPER2 could belong to a global machinery that coordinates the proliferation with the differentiation of NPCs as other molecules (FGF-4, IGF1 and TLR4) controlling both events have recently been identified [36-38]. In line with our observations, the inhibition of mPER2 synthesis in ganglionic eminence cultures results in an increased proliferation [39].

Although the molecular events triggered by mPER2 to regulate these events are not well characterized, the transcription of the proto-oncogene c-myc is deregulated in $\operatorname{Per} 2^{\mathrm{Brdm} 1}$ mice, which consequently are prone to hyperplasia and tumours [40]. Furthermore, the expression of genes involved in cell cycle regulation, such as Cyclin D1, Cyclin A, and p53, is deregulated in many tissues of Per $2^{\text {Brdm } 1}$ mice $[40,41]$. In addition, reduced levels of mPER2 expression were observed in different tumours including lymphoma, breast or endometrial cancer [4244] and the overexpression of MPER2 in tumour cells led to dramatic growth inhibition and cell cycle arrest [45]. These data are consistent with the observation that mPer2 may prevent cell cycle progression and promote the exit of the cell cycle of NPCs in the adult DG. However, the molecular pathways underlying mPer 2 activity in these cells and which role cell cycle-related genes may play to mediate these effects still need to be elucidated.

By associating with specific cyclins and cyclin-dependent kinases (Cdks) and hence blocking their catalytic activities during cell cycle progression, cyclin-dependent kinase inhibitors promote cell cycle exit at G1 restriction point in various tissues during development [46]. Among them, $\mathrm{p} 21^{\mathrm{Cip} 1}$ and $\mathrm{p} 27^{\mathrm{Kip} 1}$ are expressed in neuroblasts and newly developing neurons in the adult DG [47]. Our preliminary data suggests that $\mathrm{p} 27^{\mathrm{Kip} 1}$ expression broadly overlaps with mPER2 in early post-mitotic hippocampal immature neurons (data not shown). In addition, the proliferation and the number of $\mathrm{DCX}^{+}$cells in the adult DG, are increased in p $21^{\mathrm{cip} 1 \%}$ mice $[48,49]$. Interestingly, it has been shown recently that the circadian clock component BMAL1, regulates the expression of p21 cip1 in hepatocytes [50]. Taken together, these observations suggest $\mathrm{p} 21^{\text {cip } 1}$ and $\mathrm{p} 27^{\mathrm{kip} 1}$ as strong candidates that could act downstream mPer2 to inhibit NPCs proliferation in the adult DG. 
Unexpectedly, the number of newly formed mature granule neurons was similar in WT and Per $2^{b r d m} 1$ mice. During the first weeks following cell cycle exit, only a part of the newly generated cells find their definitive place in the hippocampal circuitry while around $50 \%$ of them are naturally eliminated through apoptosis [17,20,31]. Previous works have shown that programmed cell death is a physiological process that occurs during neurogenesis in the adult DG [51]. In Per $2^{b r d m 1}$ mice, despite an increased proliferation of NPCs and an increased number of early newborn neurons, we did not find any significant enlargement of the DG. However, we observed more TUNEL $^{+}$cells in the DG of Per2 ${ }^{b r d m} 1$. We can suggest two possible explanations for this increased cell death phenomenon. First, mPER2 may regulate the expression of pro-survival genes that would be underexpressed in $\operatorname{Per} 2^{b r d m 1}$ and lead to the death of newly born granule cells in the DG. Such selective or combined effects on distinct phases of neurogenesis have already been reported. For instance, an enriched environment is known to affect only cell survival $[14,52]$ whereas physical exercise [12], seizures [53] or absence of TLR4 [38] increase both cell proliferation and cell survival. Alternatively, the excessive cell death observed in Per $2^{b r d m} 1$ mouse DG could be an indirect consequence, i.e. a secondary and compensatory response to increased cell proliferation in Per $2^{\text {brmd } 1}$ mice. In this case, the production of new neurons in the hippocampus would be regulated by a physiological and homeostatic parapet. Similar homeostatic regulations of the formation of new neurons have been described for mCD24-deficient mice [54] or after a treatment with antidepressant drugs [55]. Reciprocally, enhanced survival of new granule cells was reported after hampering cell proliferation with methylazoxymethanol or in synapsin III knock-out mice [56,57]. Excess number of immature, $\mathrm{DCX}^{+}$and NeuroD+ neuroblasts as reported in the DG of $\operatorname{Per} 2^{\mathrm{Brdm} 1}$ mice may increase competition for trophic signals required for the maintenance of a mature DG neuronal phenotype as suggested previously [58].

Altogether, these data implied that precursor cell proliferation, cell survival, and cell differentiation are all essential events that regulate the final number of new granule neurons in the adult hippocampus. Importantly, our results show that an increased neuronal cell death prevents the accumulation of supernumerary newborn neurons in Per $2^{\text {Brdm } 1}$ mutant mice.

\section{Conclusion}

The present work has unravelled an original functional link between the constitutive expression of the circadian gene mPer 2 and the intrinsic control of NPCs proliferation, cell death and neurogenesis in the adult DG. These findings now raise new questions that include the identification of the presumably complex molecular network activated by $m P e r 2$ and required to tune the fine balance existing between cell proliferation, cell death and differentiation during adult hippocampal neurogenesis. To what extent the expression of circadian genes in the DG of the hippocampus is related or synchronized by central SCN induced rhythms remains to be elucidated. This work also emphasizes that a better understanding of the molecular cues that control circadian gene expression in the hippocampus may open new avenues to regulate neurogenesis and its yet unknown physiological function in the adult hippocampus.

\section{Methods \\ Experimental animals}

The $m$ Per $2^{\text {Brdm } 1}$ mutant mice were from Zheng et al. [27] and the CNP-EGFP mice were from Yuan et al. [30], and were propagated in the animal facility of the university of Liège. The mPer 2 gene is coding for a transcription factor possessing a PAS (Period/Arnt/Single minded) dimerization domain that is deleted in the Per $2^{\mathrm{Brdm} 1}$ mutant mice. The phenotype of our deletion mutation is consistent with a loss-of-function mutation [27]. Per2 $2^{\mathrm{Brdm} 1}$ mice maintained in a 12 hours light/12 hours night cycle present a normal locomotor activity as compare to WT mice [27]. We studied adult 45 days-old (P45) males WT and $\operatorname{Per} 2^{B r d m 1}$ mutant littermates produced from heterozygous crosses. We also used P45 CNP-EGFP mice. Artificial light was provided daily from 7 AM (Zeitgeber time ZT0) to 7 PM (ZT12) (12 hours of light/12 hours of darkness with room temperature (RT) and humidity kept constant). All animals were used in accordance with the declaration of Helsinki and following the guidelines of the Belgian ministry of agriculture in agreement with EC laboratory animal care and use regulation (86/609/CEE, CE of J n ${ }^{\circ} \mathrm{L} 358,18$ December 1986).

\section{Processing of tissue sections}

Mice were anaesthetized with Nembutal (CEVA Santé Animal, Brussels, Belgium) at selected Zeitgeber times (ZT0, ZT6, ZT12 and ZT18) before being subjected to intracardiac perfusion with $4 \%$ paraformaldehyde in PBS. Brains were removed, cryoprotected for 48 hours in 30\% sucrose/PBS solution and cut with a cryostat into $12 \mu \mathrm{m}$ thick-coronal sections for in situ hybridization or into 40 $\mu \mathrm{m}$ free-floating coronal sections for immunohistochemistry.

\section{Immunohistochemistry}

Free-floating sections were blocked for 30 minutes with blocking solution [PBS containing 5\% normal donkey serum (Jackson Immunoresearch Laboratories, West Grove, PA, U.S.A.) and 0,3\% triton X-100 (SigmaAldricht, Bornem, Belgium)]. They were then incubated one night at $4{ }^{\circ} \mathrm{C}$ in blocking solution with primary antibodies directed against mPER2 (1:250, rabbit polyclonal 
IgG, at, Alpha Diagnostic international, ADi, San Antonio, TX, U.S.A., and rabbit polyclonal IgG, 1:250, Santa Cruz, SC-25363, Heidelberg, Germany). The two antibodies give rise to similar immunolabellings. We used also primary antibodies directed against NeuN (1:250, Millipore, Brussels, Belgium), doublecortin (DCX, 1:500, Santa Cruz), NeuroD (1:100, Santa Cruz), GABA (1:750, Millipore), Sox2 (1:250, Santa Cruz) and S100 $\beta$ (1:500, DAKO, Glostrup, Denmark). After washing three times with PBS, sections were reacted at RT for 2 hours with RRX-, FITC- or Cy 5-conjugated secondary antibodies (1:500, Jackson Immunoresearch Laboratories). After washing, sections were finally incubated with the nucleic acid stain TO-PRO ${ }^{\circledR}-3$ (1:1500 in PBS, Molecular Probes, Eugene, U.S.A.) and coverslipped using the Vectashield mounting medium (Hard Set Mounting Medium, Vector laboratories, Burlingame, U.S.A.), or directly mounted with the Vectashield mounting medium containing the nucleic acid counterstain DAPI (Vector laboratories). The slides were stored in the dark at $4^{\circ} \mathrm{C}$. Controls were performed by omitting primary antibodies, which in all cases resulted in a complete loss of immunofluorescence signal.

\section{Demonstration of antibody specificity}

The synthetic blocking peptide PER21-P is incubated with mPER2 antibody. PER21-P (approximately $5 \mu \mathrm{g}$ ) and control PBS solutions were incubated overnight at $4^{\circ} \mathrm{C}$ both in the presence of anti-mPER2 antibody (approximately 1 $\mu \mathrm{g})$ diluted at usual concentration $(1 / 250)$. After centrifugation at 15000 RPM to pellet any immune complexes, the supernatants were removed and used for immunostainings (See Additional file 1).

\section{Assessment of cell proliferation and neurogenesis}

Brain sections were stained for Ki67 (1:100, mouse, BD Biosciences, San Jose, CA, U.S.A.), a nuclear marker of cell division that is expressed in all phases of the cell cycle (G1-S-G2-M). In order to study specifically S-phase dividing cells, WT and Per $2^{\text {Brdm1 }}$ mice were injected with 5'bromo-2-deoxyuridine (BrdU) (i.p. injection at $100 \mathrm{mg} /$ kg of body weight; Sigma-Aldrich) and were sacrificed 2 hours later. For immunohistochemical detection of BrdUincorporating nuclei, free-floating sections were incubated in $2 \mathrm{~N} \mathrm{HCl}$ for 30 minutes at $37^{\circ} \mathrm{C}$. Sections were then incubated in a $0,1 \mathrm{M}$ borate buffer solution ( $\mathrm{pH} 8.5)$, rinsed three times in PBS and stained for BrdU (1:500, rat IgG2a, Immunosource, Raleigh, U.S.A.) as described above.

To assess the total number of newborn neurons in the adult DG, P45 WT and Per $2^{\text {Brdm } 1}$ mice received one injection of BrdU (i.p. injection at $100 \mathrm{mg} / \mathrm{kg}$ of body weight) and were sacrificed four days later ("short-term" assessment of neurogenesis) or received one daily injection during five days and sacrificed three weeks later ("long-term" assessment of neurogenesis). We then analyzed the fate of
BrdU-tagged newborn cells in the adult DG by coupling BrdU and NeuN immunostainings.

\section{Cell death detection}

To study the cell death, the terminal dUTP-biotin nick end labelling (TUNEL) was used [59] on $40 \mu$ m-thick freefloating sections of P45 WT and Per $2^{\text {Brdm } 1}$ mice. Sections were treated 30 minutes with $1 \%$ triton X-100 and preincubated 10 minutes in TdT buffer (30 mM Tris, pH 7,5, containing $140 \mathrm{mM}$ sodium cacodylate and $1 \mathrm{mM}$ cobalt chloride). Sections were then incubated in TdT buffer containing $300 \mathrm{U} / \mathrm{ml}$ TdT (Roche Applied Science) and $6 \mu \mathrm{M}$ biotinylated dUTP (Roche Applied Science) in a humid chamber for 90 minutes at $37^{\circ} \mathrm{C}$. The reaction was stopped by a 15 minutes rinse at RT in TB buffer $(300 \mathrm{mM}$ $\mathrm{NaCl}, 30 \mathrm{mM}$ sodium citrate, $\mathrm{pH} 7,4)$. Sections were incubated 10 minutes with 2\% BSA (bovine serum albumin fraction V, Sigma-Aldrich) in PBS to minimize non-specific staining. Biotin-dUTP-labeled sections were then incubated with Alexa568-conjugated streptavidin (1:1000, Jackson Immunoresearch Laboratories) for one hour at RT. Finally, fluorescent immunohistochemical staining for BrdU was performed on TUNEL labelled sections as described above.

\section{In situ hybridization}

The sequence of the antisense probe was made from a DNA template corresponding to mPer2 nucleotides 229768 (AF036893). RNA probes were prepared by in vitro transcription with the digoxigenin labelling kit (Roche Applied Science) using T7 RNA polymerase for sense probe and T3 polymerase for antisense. $12 \mu \mathrm{m}$-thick adherent sections were acetylated 15 minutes, and dehydrated. After three washes with PBS-Tween 0,1\%, sections were pre-hybridized with pre-warmed hybridization buffer (Amresco, Ohio, U.S.A.) for 60 minutes at $55^{\circ} \mathrm{C}$. Sections were then hybridized one night at $55^{\circ} \mathrm{C}$ with 800 $\mathrm{ng} / \mathrm{ml}$ mPer2 RNA probe. The next day, sections were washed twice with pre-warmed washing buffer (formamide $50 \%, 0,1 \%$ of tween, SSC $20 \times$ in $\mathrm{H}_{2} 0$ ) for 60 minutes at $65^{\circ} \mathrm{C}$. Sections were then incubated one night at $4{ }^{\circ} \mathrm{C}$ with an anti-digoxigenin antibody coupled to alkaline phosphatase (1:2000, Roche Applied Science) in buffer composed of Tris-HCl $100 \mathrm{mM} \mathrm{pH} \mathrm{7,5,} \mathrm{NaCl} 150$ $\mathrm{mM}, 0,1 \%$ of Tween-20, and $10 \%$ goat serum (DAKO). Sections were overlaid with $200 \mu \mathrm{l}$ filtered NBT/BCIP/ Tween-20 0,1\% solution (Sigma-Aldrich) between coverslips for six hours. Sections were then washed three times in PBS to stop the reaction and post-fixed 15 minutes with PFA 4\%. Sections were then processed for immunohistochemistry as described above.

\section{Neural stem/progenitor cells culture}

The primary cell culture technique used was the neurosphere assay [60]. The DG of three WT or three Per $2^{\text {Brdm } 1}$ P10 mice were removed and incubated whit Earl's Bal- 
anced Salt Solution (Invitrogen, Merelbeke, Belgium) containing one $\mathrm{mg} / \mathrm{ml}$ of papain (Worthington, Lakewood, U.S.A.) and $500 \mu \mathrm{l}$ of DNAse $0,1 \%$ (Sigma-Aldrich) for 35 minutes at $37^{\circ} \mathrm{C}$. After mechanical dissociation, cells were suspended in culture $\left(10^{4} \mathrm{cells} / \mathrm{cm}^{2}\right)$ in DMEM/ F12/B27 medium with epidermal growth factor (20 ng/ $\mathrm{ml}$, PeproTech, London U.K.) and basic fibroblast growth factor $(10 \mathrm{ng} / \mathrm{ml}$, PeproTech). Primary spheres obtained after five days were dissociated in enzyme solution (as above) and dissociated cells were re-suspended into fresh medium solution at $10^{4}$ cells $/ \mathrm{cm}^{2}$. It has been previously demonstrated that culturing cells at this density resulted in clonal neurosphere colonies, as formed in single-cell cultures. Neurospheres do not arise as a result of cell aggregation at this cell culture density $[61,62]$. All experiments were performed between passage two and three. Neurospheres size was determined by measuring the diameter of individual neurosphere (assuming a spherical shape) using ImageJ software.

Neural stem cell differentiation was induced in neurospheres plated onto poly-L-ornithin $(15 \mu \mathrm{g} / \mathrm{ml})$ and laminin $(10 \mu \mathrm{g} / \mathrm{ml})$ coated coverslips in DMEM/F12 supplemented with $1 \%$ fetal bovine serum (Invitrogen), B27 with vitamin A (Invitrogen) and $20 \mathrm{ng} / \mathrm{ml}$ of brainderived neurotrophic factor (PeproTech). After five days of differentiation, neurospheres were fixed in $4 \%$ PFA and processed for immunocytochemistry as described above with primary antibodies against GFAP $(1: 100$, DAKO), $\beta$ III tubulin (1:500, Tuj1 clone, Babco, Richmond, CA, U.S.A.), O4 (1:100, Millipore) and nestin (1:250, Novus, Littleton, U.S.A.). All these experiments were done in triplicate.

\section{Image acquisition and analysis}

Immunostained sections were imaged using the Olympus Fluoview FV1000 confocal system equipped with the Olympus IX81 inverted microscope (Olympus Europa GmbH, Hamburg, Germany). For each $40 \mu \mathrm{m}$-thick section, the whole DG, was Z-scanned using the $40 \times$ objective, and the composite of the "Z-stack» images was analyzed. All sections prepared for comparison were stained at the same time, in the same conditions and were selected at the same stereological location.

Drawing a box across the GCL and measuring the mean intensity value in pixels determined fluorescence intensity of mPER2 levels. Background value taken from unlabeled areas was subtracted from measured value for every field analyzed. Three separate sections were analyzed, in three different animals and Prism software was used for statistical analysis, and Student's $t$-test was used to determine significance levels.

To estimate the total number of immunolabelled cells in the GCL of the DG, we used a modified version of the optical fractionator method, as recently described [63,64]. Briefly, a systematic random sampling of every sixth 40$\mu \mathrm{m}$ coronal section $(240 \mu \mathrm{m})$ along the rostro-caudal axis of the DG $(-1.06 \mathrm{~mm}$ to $-3.80 \mathrm{~mm}$ form bregma) was selected from each animal and processed for immunohistochemistry. Immunopositive cells in the GCL were counted under a 40x-magnification microscope objective. The total number of positive cells was estimated by multiplying the results by six (because every sixth section were used) to provide an estimate of the total number of cells per DG.

To estimate any volumetric discrepancy between the DG of WT and Per $2^{\text {Brdm } 1}$ mice, we compared similar GCL areas between WT and Per $2^{B r d m} 1$ mice using adjacent coronal sections throughout the entire rostral/caudal extent of the hippocampus (from Bregma $-1.06 \mathrm{~mm}$ to Bregma -3.80 $\mathrm{mm}$ ) as previously described [65]. Every sixth $40 \mu \mathrm{m}$-thick section has been NeuN immunostained and imaged. Using ImageJ software, the GCL has been outlined and the area obtained. Volume has been estimated using the formula $\Sigma$ AxTxI, where $\Sigma \mathrm{A}$ is the sum of the area measured on each section, $\mathrm{T}$ is the section thickness, and $\mathrm{I}$ is the number of section intervals. The number of sections varied between genotypes; thus, sampling began at the first indication of a complete DG and ended when the DG was no longer visible. We showed that there were no volumetric differences between GCL of the hippocampus of the WT and Per $2^{\text {Brdm1 } 1}$ mice (See Additional file 3).

\section{Western Blotting}

Mice were killed at ZT0, ZT6, ZT12 or ZT18 by cervical dislocation. Brains from P45 WT mice were removed, placed rostral-side up in $35 \mathrm{~mm}$ Petri dishes and covered with a $3 \%$ solution of low-gelling temperature agarose at $37^{\circ} \mathrm{C}$ and then immediately placed at $4^{\circ} \mathrm{C}$ to harden the agarose solution. Brains were cut on a vibratome (Leica, Zaventem, Belgium) into viable $700 \mu \mathrm{m}$ coronal sections in icecold PBS solution containing $30 \%$ glucose, and the DG of the hippocampus or the SCN were removed under a dissecting microscope. Tissues were lysed on ice using $200 \mu \mathrm{l}$ of lysis buffer [Hepes $10 \mathrm{mM} \mathrm{pH} 7,9, \mathrm{KCl} 10 \mathrm{mM}, \mathrm{MgCl}_{2}$ $2 \mathrm{mM}$, EDTA 0, $1 \mathrm{mM}$, Igepal ${ }^{\mathrm{TM}} 0,1 \%$ (Sigma-Aldrich), DTT $1 \mathrm{mM}$, PMSF $1 \mathrm{mM}$ and protease inhibitors cocktail (Roche Applied Science)]. After five minutes on ice, the samples were centrifuged 5 minutes at $2000 \mathrm{~g}$. The pellet was washed two times with $500 \mu \mathrm{l}$ of washing buffer [Hepes $10 \mathrm{mM}, \mathrm{pH} 7,9, \mathrm{KCl} 20 \mathrm{mM}, \mathrm{MgCl}_{2} 2 \mathrm{mM}$, EDTA $0,1 \mathrm{mM}$, DTT $1 \mathrm{mM}$, PMSF $1 \mathrm{mM}$, and protease inhibitors cocktail]. The samples were then homogenized with $50 \mu \mathrm{l}$ of extraction buffer [Hepes $20 \mathrm{mM} \mathrm{pH} \mathrm{7,9,} \mathrm{MgCl2} \mathrm{1,5}$ $\mathrm{mM}$, EDTA 0,02 mM, $\mathrm{NaCl}$ 0,63 mM, $\mathrm{H}_{2} 0$, Glycerol 25\%, DTT 0,5 mM, PMSF $1 \mathrm{mM}$, protease inhibitors cocktail] and incubated for 30 minutes on ice and 10 minutes at $80^{\circ} \mathrm{C}$. The homogenates were then centrifuged at $14000 \mathrm{~g}$ for 30 minutes at $4^{\circ} \mathrm{C}$. The supernatants were used as 
nuclear fraction and the protein concentration was determined using RC DC Protein Assay (Bio-Rad, Nazareth, Belgium). Nuclear protein lysates $(20 \mu \mathrm{g})$ were then mixed with an equal volume of loading buffer (glycerol $20 \%$, SDS $4 \%$, Tris $100 \mathrm{mM}, \beta$-mercaptoethanol $5 \%$ and bromophenol blue) before being boiled for three minutes. Proteins were then loaded on a 7,5\% SDS-polyacrylamide gel electrophoresis, and the gel run 20 minutes at 100 volts. Proteins contained in the gel were transferred on a polyvinylidene difluoride membrane (Amersham, Roosendaal, The Netherlands) by semi-dry electroblotting in transfer buffer (Glycine $192 \mathrm{mM}$, Tris $25 \mathrm{mM}$ and methanol 20\%). Membranes were then blocked one hour at RT in 0,2\% I-BLOCK (TROPIX, Bedford, MA, U.S.A.) diluted in TBS supplemented with 0,05\% Tween 20 (BioRad) (TTBS) corresponding to the blocking buffer. Membranes were incubated one night at $4{ }^{\circ} \mathrm{C}$ in the blocking buffer containing the primary antibody directed against mPER2 (H-90) (1:2500 in the blocking buffer, SC-25363, Santa Cruz or Per21 A, ADi). After washing three times with TTBS, the membranes were incubated with peroxidase-conjugated polyclonal anti-rabbit antibody (1:3000, ABCAM, Cambridge, U.K.) one hour at RT. Blots were then washed extensively with TTBS and developed using enhanced chemoluminescence ECL substrate (Pierce, Aalst, Belgium). Membranes were stripped with Restore ${ }^{\mathrm{TM}}$ blot stripping buffer (Pierce), wash three times in TTBS and incubated one night at four ${ }^{\circ} \mathrm{C}$ with BAF57 antibody (1:2500, rabbit, Sigma-Aldrich). After washing, the membranes were incubated with peroxidase-conjugated antirabbit antibody (1:3000, ABCAM) and developed as described above. Quantification of the bands was carried out by densitometric analysis using Image J software.

\section{Abbreviations}

BrdU: 5'-bromo-2-deoxyuridine; cdk: cylin-dependent kinase; DCX: doublecortin; DG: dentate gyrus; DNA: deoxyribonucleic acid; GCL: granule cell layer; H: hilus; i.p: intra-peritoneal; mPer1: period 1 gene; mPer2: period 2 gene; MPER2: period 2 protein; $m$ Per3: period 3 gene; mRNA: ribonucleic acid; NPC: neural progenitor/stem cell; PBS: phosphate buffer saline; Per2 ${ }^{\text {Brmd1 }}$ : per2 mutant mice; PFA: paraformaldehyde; RT: room temperature; SCN: suprachiasmatic nuclei; SGL: subgranular layer; TBS: tris buffer solution; TTBS: tween-20/tris buffer solution; TUNEL: terminal dUTP-biotin nick end labelling; WT: wild-type; ZT: Zeitgeber.

\section{Authors' contributions}

$\mathrm{LB}, \mathrm{PB}, \mathrm{RV}$ carried out the studies and participated in the data analysis. LB, LN, SB, BM conceived the study, participated in its design and helped to draft the manuscript. GM and PM contributed to the conception and design of the project. UA produced the mice and helped in the last version of the manuscript. All the authors read and approved the final manuscript.

\section{Additional material}

\begin{abstract}
Additional file 1
Expression of mPER2 protein in adult dentate gyrus sections using different antibodies. (A-B) Panels representing confocal images of DG sections simultaneously processed for immunostaining with ADi Per2 antibody (A) or Santacruz Per2 antibody (B) at ZT12. The two antibodies recognize identically mPER2. (C) Western blot analysis were carried out on nuclear protein extracts from micro-dissected SCN and DG at ZT12. Both ADi and Santacruz antibodies yielded bands at the expected size $(136 \mathrm{kDa})$. (D-I) anti-PER2 antibody was pre-incubated with Per21-P blocking peptide (D-F) or not (G-I) before immunolabelling procedure. Nuclear counterstaining was obtained using To-Pro ${ }^{\circledast}(E, H)$. Scale bar in $A=50 \mathrm{~m}$ for $A-B, 40 \mathrm{~m}$ for D-I.

Click here for file

[http://www.biomedcentral.com/content/supplementary/14712202-10-30-S1.tiff]
\end{abstract}

\section{Additional file 2}

mPER2 is expressed in GABAergic neurons but not in astroglial and oligodendroglial cells in the adult dentate gyrus. White arrow point towards a neural stem/progenitor cell located in the SGL of the DG expressing mPER2 (A) and Sox2 (B). (C) This cell is negative for the astroglial marker $\mathrm{S} 100$ (C). Astroglial cell co-expressing S100 and Sox2 (white arrowhead A-D) is mPer2 negative. (E-G) mPER2 and CNPEGFP expression in the DG of P45 WT mice. White arrows point towards CNP-EGFP+ oligodendrocytes that were all mPER2-(H-J) A significant proportion of mPER2+ neurons (white arrows) in the hilar region $(H)$ and granule cell layer (GCL) of the DG were $\mathrm{GABA}^{+}$. Scale bar in $A=25 \mathrm{~m}$ for $A-D$ and $50 \mathrm{~m}$ for $E-J$.

Click here for file

[http://www.biomedcentral.com/content/supplementary/14712202-10-30-S2.tiff]

\section{Additional file 3}

No significant difference between the volume of the dentate gyrus in WT and Per $2^{\mathrm{Brdm} 1}$ mice. (A-B) Confocal images of coronal sections of the DG counterstained with NeuN in order to study the absence of morpho-volumetric differences between WT and $\mathrm{mPer} 2^{\mathrm{Brdm} 1}$ mutant mice at the same level of the rostro-caudal axis. (C) We have compared similar hippocampal areas between $\mathrm{WT}$ and $\mathrm{mPer} 2^{\mathrm{Brdm} 1}$ mutant mice and observed that the volume of the granule cell layer (GCL) was not significantly different between the two genotypes (Student's t-test, $n=3, p>$ $0,05)$. Scale bar in $A=300 \mathrm{~m}$ for $A-B$.

Click here for file

[http://www.biomedcentral.com/content/supplementary/14712202-10-30-S3.tiff]

\section{Acknowledgements}

This work was supported by a concerted action of the French Community of Belgium (Convention $N^{\circ}$ 04/09-322), by the convention $N^{\circ} 3.4514 .05$ from the Fonds de la Recherche Scientifique Médicale (F.R.S.M., Belgium), and by the Fonds Léon Frédéricq. We are particularly grateful to Maria Chiara Magnone (Division of Biochemistry, University of Fribourg, Switzerland) for sharing her unpublished observations and for valuable discussion. We thank Vittorio Gallo (Children's National Medical Center, Washington DC, 
U.S.A.) for stimulating discussions. SB is a research associate and BM is a senior research associate of the F.N.R.S. (Belgium). RV was supported by the Association Européenne contre les Leukodystrophies (E.L.A.).

\section{References}

I. Song HJ, Stevens CF, Gage FH: Neural stem cells from adult hippocampus develop essential properties of functional CNS neurons. Nat Neurosci 2002, 5:438-445.

2. van Praag H, Schinder AF, Christie BR, Toni N, Palmer TD, Gage FH: Functional neurogenesis in the adult hippocampus. Nature 2002, 415: 1030-1034

3. Kempermann G: Why new neurons? Possible functions for adult hippocampal neurogenesis. I Neurosci 2002, 22(3):635-638.

4. Matsuo T, Yamaguchi S, Mitsui S, Emi A, Shimoda F, Okamura H: Control mechanism of the circadian clock for timing of cell division in vivo. Science 2003, 302:255-259.

5. Kempermann G, Jessberger S, Steiner B, Kronenberg G: Milestones of neuronal development in the adult hippocampus. Trends Neurosci 2004, 27:447-452.

6. Gould E, Tanapat P, Cameron HA: Adrenal steroids suppress granule cell death in the developing dentate gyrus through an NMDA receptor-dependent mechanism. Brain Res Dev Brain Res 1997, 103:91-93.

7. Gould E, McEwen BS, Tanapat P, Galea LA, Fuchs E: Neurogenesis in the dentate gyrus of the adult tree shrew is regulated by psychosocial stress and NMDA receptor activation. J Neurosci 1997, 17:2492-2498.

8. Brezun JM, Daszuta A: Depletion in serotonin decreases neurogenesis in the dentate gyrus and the subventricular zone of adult rats. Neuroscience 1999, 89:999-1002.

9. Jacobs BL, van Praag H, Gage FH: Adult brain neurogenesis and psychiatry: a novel theory of depression. Mol Psychiatry 2000, 5:262-269.

10. Kempermann G, Gast D, Gage FH: Neuroplasticity in old age: sustained fivefold induction of hippocampal neurogenesis by long-term environmental enrichment. Ann Neurol 2002, 52:135-143.

II. Kuhn HG, Dickinson-Anson H, Gage FH: Neurogenesis in the dentate gyrus of the adult rat: age-related decrease of neuronal progenitor proliferation. J Neurosci 1996, 16(6):2027-2033.

12. van Praag H, Kempermann G, Gage FH: Running increases cell proliferation and neurogenesis in the adult mouse dentate gyrus. Nat Neurosci 1999, 2:266-270.

13. Guzman-Marin R, Suntsova N, Stewart DR, Gong H, Szymusiak R, McGinty D: Sleep deprivation reduces proliferation of cells in the dentate gyrus of the hippocampus in rats. J Physiol 2003, 549:563-57I.

14. Kempermann G, Kuhn HG, Gage FH: More hippocampal neurons in adult mice living in an enriched environment. Nature 1997, 386:493-495.

15. Goergen EM, Bagay LA, Rehm K, Benton JL, Beltz BS: Circadian control of neurogenesis. I Neurobiol 2002, 53:90-95.

16. Balsalobre A, Damiola F, Schibler U: A serum shock induces circadian gene expression in mammalian tissue culture cells. Cell 1998, 93:929-937.

17. Hastings MH, Reddy AB, Maywood ES: A clockwork web: circadian timing in brain and periphery, in health and disease. Nat Rev Neurosci 2003, 4:649-66I.

18. Albrecht U, Sun ZS, Eichele G, Lee CC: A differential response of two putative mammalian circadian regulators, mperl and mper2, to light. Cell 1997, 91 : I055-1064.

19. Tei H, Okamura H, Shigeyoshi Y, Fukuhara C, Ozawa R, Hirose M, Sakaki Y: Circadian oscillation of a mammalian homologue of the Drosophila period gene. Nature 1997, 389:5।2-516.

20. Cameron HA, McKay RD: Adult neurogenesis produces a large pool of new granule cells in the dentate gyrus. J Comp Neurol 200I, 435:406-4I7.

21. Bjarnason GA, Jordan R: Circadian variation of cell proliferation and cell cycle protein expression in man: clinical implications. Prog Cell Cycle Res 2000, 4:193-206.

22. Garcia MN, Barbeito CG, Andrini LA, Badran AF: Circadian rhythm of DNA synthesis and mitotic activity in tongue keratinocytes. Cell Biol Int 200I, 25:179-183.
23. Brown WR: A review and mathematical analysis of circadian rhythms in cell proliferation in mouse, rat, and human epidermis. J Invest Dermatol 1991, 97:273-280.

24. Smaaland R: Circadian rhythm of cell division. Prog Cell Cycle Res 1996, 2:24I-266.

25. Shearman LP, Zylka MJ, Weaver DR, Kolakowski LF Jr, Reppert SM: Two period homologs: circadian expression and photic regulation in the suprachiasmatic nuclei. Neuron 1997, 19:126I-1269.

26. Zylka MJ, Shearman LP, Weaver DR, Reppert SM: Three period homologs in mammals: differential light responses in the suprachiasmatic circadian clock and oscillating transcripts outside of brain. Neuron 1998, 20: I 103-III0.

27. Zheng B, Larkin DW, Albrecht U, Sun ZS, Sage M, Eichele G, Lee CC, Bradley $A$ : The mPer2 gene encodes a functional component of the mammalian circadian clock. Nature 1999, 400:169-173.

28. Abrous DN, Koehl M, Le MM: Adult neurogenesis: from precursors to network and physiology. Physiol Rev 2005, 85:523-569.

29. Zhao C, Deng W, Gage FH: Mechanisms and functional implications of adult neurogenesis. Cell 2008, 132:645-660.

30. Yuan X, Chittajallu R, Belachew S, Anderson S, McBain CJ, Gallo V: Expression of the green fluorescent protein in the oligodendrocyte lineage: a transgenic mouse for developmental and physiological studies. J Neurosci Res 2002, 70:529-545.

31. Dayer AG, Ford AA, Cleaver KM, Yassaee M, Cameron HA: Shortterm and long-term survival of new neurons in the rat dentate gyrus. J Comp Neurol 2003, 460:563-572.

32. Schibler U: The daily rhythms of genes, cells and organs. Biological clocks and circadian timing in cells. EMBO Rep 2005, 6(Spec No):S9-13.

33. Alvarez JD, Sehgal A: The thymus is similar to the testis in its pattern of circadian clock gene expression. J Biol Rhythms 2005, 20:111-|2|

34. Morse D, Cermakian N, Brancorsini S, Parvinen M, Sassone-Corsi P: No circadian rhythms in testis: Periodl expression is clock independent and developmentally regulated in the mouse. Mol Endocrinol 2003, 17:|4|-|5|.

35. Alvarez JD, Chen D, Storer E, Sehgal A: Non-cyclic and developmental stage-specific expression of circadian clock proteins during murine spermatogenesis. Biol Reprod 2003, 69:8I-91.

36. Arsenijevic Y, Villemure JG, Brunet JF, Bloch JJ, Deglon N, Kostic C, Zurn A, Aebischer P: Isolation of multipotent neural precursors residing in the cortex of the adult human brain. Exp Neurol 200I, 170:48-62.

37. Kosaka N, Kodama M, Sasaki H, Yamamoto Y, Takeshita F, Takahama Y, Sakamoto H, Kato T, Terada M, Ochiya T: FGF-4 regulates neural progenitor cell proliferation and neuronal differentiation. FASEB / 2006, 20: | 484-I 485

38. Rolls A, Shechter R, London A, Ziv Y, Ronen A, Levy R, Schwartz M: Toll-like receptors modulate adult hippocampal neurogenesis. Nat Cell Biol 2007, 9: I08I-I088.

39. Moriya T, Hiraishi K, Horie N, Mitome M, Shinohara K: Correlative association between circadian expression of mousePer2 gene and the proliferation of the neural stem cells. Neuroscience 2007, I46:494-498.

40. Fu L, Pelicano H, Liu J, Huang P, Lee C: The circadian gene Period2 plays an important role in tumor suppression and DNA damage response in vivo. Cell 2002, I I I:4 I-50.

4I. Lee CC: Tumor suppression by the mammalian Period genes. Cancer Causes Control 2006, 17:525-530.

42. Gery S, Gombart AF, Yi WS, Koeffler C, Hofmann WK, Koeffler HP: Transcription profiling of C/EBP targets identifies Per2 as a gene implicated in myeloid leukemia. Blood 2005, 106:2827-2836.

43. Chen ST, Choo KB, Hou MF, Yeh KT, Kuo SJ, Chang JG: Deregulated expression of the PERI, PER2 and PER3 genes in breast cancers. Carcinogenesis 2005, 26: | 24|- 1246.

44. Shih HC, Choo KB, Chang TJ, Yang MY, Shih MC, Yeh KT, Liu TC, Lin SF, Chang JG: Disturbance of circadian gene expression in endometrial cancer: detection by real-time quantitative $R T$. PCR. Oncol Rep 2005, I4:1533-1538.

45. Hua $H$, Wang $Y$, Wan $C$, Liu $Y$, Zhu B, Yang C, Wang $X$, Wang Z, Cornelissen-Guillaume G, Halberg F: Circadian gene mPer2 overexpression induces cancer cell apoptosis. Cancer Sci 2006, 97:589-596. 
46. Sherr C], Roberts JM: CDK inhibitors: positive and negative regulators of GI-phase progression. Genes Dev 1999, 13:1501-1512.

47. Schmetsdorf S, Gartner U, Arendt T: Expression of cell cyclerelated proteins in developing and adult mouse hippocampus. Int J Dev Neurosci 2005, 23:10 I- I I2.

48. Pechnick RN, Zonis S, Wawrowsky K, Pourmorady J, Chesnokova V: p2 ICipI restricts neuronal proliferation in the subgranular zone of the dentate gyrus of the hippocampus. Proc Natl Acad Sci USA 2008, 105:1358-1363.

49. Kippin TE, Martens DJ, van der KD: p2I loss compromises the relative quiescence of forebrain stem cell proliferation leading to exhaustion of their proliferation capacity. Genes Dev 2005, 19:756-767.

50. Grechez-Cassiau A, Rayet B, Guillaumond F, Teboul M, Delaunay F: The Circadian Clock Component BMALI Is a Critical Regulator of p2IWAFI/CIPI Expression and Hepatocyte Proliferation. J Biol Chem 2008, 283:4535-4542.

5I. Biebl M, Cooper CM, Winkler J, Kuhn HG: Analysis of neurogenesis and programmed cell death reveals a self-renewing capacity in the adult rat brain. Neurosci Lett 2000, 29 I:17-20.

52. Gould E, Beylin A, Tanapat P, Reeves A, Shors TJ: Learning enhances adult neurogenesis in the hippocampal formation. Nat Neurosci 1999, 2:260-265.

53. Parent JM, Yu TW, Leibowitz RT, Geschwind DH, Sloviter RS, Lowenstein $\mathrm{DH}$ : Dentate granule cell neurogenesis is increased by seizures and contributes to aberrant network reorganization in the adult rat hippocampus. J Neurosci 1997, 1 7:3727-3738

54. Belvindrah R, Rougon G, Chazal G: Increased neurogenesis in adult mCD24-deficient mice. J Neurosci 2002, 22:3594-3607.

55. Sairanen M, Lucas G, Ernfors P, Castren M, Castren E: Brainderived neurotrophic factor and antidepressant drugs have different but coordinated effects on neuronal turnover, proliferation, and survival in the adult dentate gyrus. J Neurosci 2005, 25:1089-1094.

56. Ciaroni S, Cecchini T, Ferri P, Ambrogini P, Cuppini R, Riccio M, Lombardelli G, Papa S, Del GP: Impairment of neural precursor proliferation increases survival of cell progeny in the adult rat dentate gyrus. Mech Ageing Dev 2002, I 23:134|-| 352.

57. Kao HT, Li P, Chao HM, Janoschka S, Pham K, Feng J, McEwen BS, Greengard P, Pieribone VA, Porton B: Early involvement of synapsin III in neural progenitor cell development in the adult hippocampus. J Comp Neurol 2008, 507:1860-1870.

58. Minichiello $L$, Klein R: TrkB and TrkC neurotrophin receptors cooperate in promoting survival of hippocampal and cerebellar granule neurons. Genes Dev 1996, 10:2849-2858.

59. Gavrieli Y, Sherman Y, Ben-Sasson SA: Identification of programmed cell death in situ via specific labeling of nuclear DNA fragmentation. J Cell Biol 1992, I 19:493-50I.

60. Reynolds BA, Weiss S: Generation of neurons and astrocytes from isolated cells of the adult mammalian central nervous system. Science 1992, 255: 1707-1710.

61. Morshead CM, Craig CG, van der KD: In vivo clonal analyses reveal the properties of endogenous neural stem cell proliferation in the adult mammalian forebrain. Development 1998, I 25(I 2):225|-226I.

62. Tropepe V, Hitoshi S, Sirard C, Mak TW, Rossant J, van der KD: Direct neural fate specification from embryonic stem cells: a primitive mammalian neural stem cell stage acquired through a default mechanism. Neuron 200I, 30:65-78.

63. Plumpe T, Ehninger D, Steiner B, Klempin F, Jessberger S, Brandt M, Romer B, Rodriguez GR, Kronenberg G, Kempermann G: Variability of doublecortin-associated dendrite maturation in adult hippocampal neurogenesis is independent of the regulation of precursor cell proliferation. BMC Neurosci 2006, 7:77.

64. Cameron HA, McKay RD: Restoring production of hippocampal neurons in old age. Nat Neurosci 1999, 2:894-897.

65. Chumley MJ, Catchpole T, Silvany RE, Kernie SG, Henkemeyer M: EphB receptors regulate stem/progenitor cell proliferation, migration, and polarity during hippocampal neurogenesis. Neurosci 2007, 27: 1348I-13490.
Publish with Biomed Central and every scientist can read your work free of charge

"BioMed Central will be the most significant development for disseminating the results of biomedical research in our lifetime. "

Sir Paul Nurse, Cancer Research UK

Your research papers will be:

- available free of charge to the entire biomedical community

- peer reviewed and published immediately upon acceptance

- cited in PubMed and archived on PubMed Central

- yours - you keep the copyright
BioMedcentral 